\title{
Zollinger Ellison Syndrome
}

National Cancer Institute

\section{Source}

National Cancer Institute. Zollinger Ellison Syndrome. NCI Thesaurus. Code C3453.

A syndrome characterized by the presence of a gastrin-secreting tumor, usually in the pancreas or duodenum, resulting in increased gastric acidity and formation of gastric ulcers. Signs and symptoms include abdominal pain and diarrhea. It may be sporadic or a manifestation of multiple endocrine neoplasia type 1. 